\title{
La Penitencia y sus Formas
}

Examen de su evoluciòn històrica

\section{ALGUNAS OBSERVACIONES}

No es mi intención presentar un elenco exhaustivo de todas las mitigaciones que han existido a lo largo de la historia. Sin duda que han sido no pocas mitigaciones más que las que referiré en estas páginas. Unicamente quisiera seleccionar ciertos hechos históricos que atestiguan algunas de las más significativas en relación con el título que encabeza estas líneas.

Tampoco quisiera dar un sentido absoluto al pensamiento desarrollado en estas páginas: la afirmación de que las formas penitenciales han caminado a lo largo de la historia, lenta pero progresivamente, en el sentido de una mayor benignidad, imponiéndose cada vez más el pensamiento de la misericordia divina, como principio fundamental -corriente que llamaré benigna - frente a la corriente inclinada al rigorismo. Esta afirmación deseo que se interprete en sentido estricto y restringido. Me refiero, pues, única y exclusivamente a las formas institucionales de exteriorización de la penitencia interna, y no a la misma penitencia interna del corazón que es lo esencial y que ha permanecido y permanecerá inmutable siempre en sus exigencias. No centro mi atención sobre el número de pecados sometibles necesariamente a la penitencia. En cuanto a esto constatamos un aumento continuado del número de pecados que obligatoriamente se han de someter a las formas penitenciales. Creo que podríamos afirmar, sin correr el riesgo de falsificación, que, a medida que las formas insti- 
tucionales penitenciales eran mitigadas, aumentaba el número de los pecados a ellas sometibles, o sometendos ${ }^{1}$.

Es difícil confeccionar un esquema homogéneo que permita ver una evolución constante y sin interrupción de las formas penitenciales oficiales sacramentales hacia una mayor benignidad. Un correr progresivo hacia la benignidad sería fácil establecerlo si se comparan entre sí los diversos períodos de la evolución de las formas institucionales penitenciales. Pero no es tan fácil probar tal afirmación cuando se centra uno de forma exclusiva en un periodo concreto. En el primer período que, en mi opinión, abarcaría todo el tiempo que transcurre desde el nacimiento de la Iglesia hasta el aparecer de la penitencia tarifada, es difícil llegar a una conclusión definitiva, puesto que se encuentran opiniones con las más variadas direcciones. Dentro del período que se denomina de la "penitencia tarifada", en cambio, podemos fijar una serie de constataciones que incrementan y fortifican el caminar hacia la benignidad ${ }^{2}$. Finalmente, a partir del siglo XII, con la elaboración teológica que se inicia en este siglo, afianzada por la fijación del Concilio Lateranense IV y finalmente

1. "Il se peut que, ça et là et dans certains cas, quelques autres péchés aient été aussi primitivement punis de l'exclusion; il est facile d'observer notamment que le nombre des fautes canoniques augmenta avec le temps. Mais malgré cela la triade originelle demeure clairement reconnaissable, et ainsi l'idolatrie, le meurtre et la luxure comptaient seuls dans le principe comme péchés capitaux" (E. VACCANDARD, "e pouvoir des clets et la confession sacramentelie. A propos d'un livre récent. I: La discipline pénitentielle dans l'Eglise depuis les origines jusqu'au XII siècle": Revue du Clergé Françals 14 (1898) 196; 16 (1898) 426. Igualmente pueden consultarse: M. FUNCK, "Busse": Real-Encyclopedie der christlichen Altertumer de F. X. Kraus, Freiburg I. Br. 1882. Conviene indicar que FUNCK, "Bussdiszplin": Kirchenlexicon, de Welzer et Welte, Freiburg 1. Br. 1883, II, 1561s, retoca el articulo anteriormente citado y que finalmente en su Kirchengeschichte Abhandiungen und Untersuchungen, I, Paderborn 1897, 155-181, 182-209 expone sus últimas conclusiones sobre la cuestión; H. RONDET, "Esquisse d'une histoire du sacrement de Pénitence": Nouvelle Revue Théologique 80 (1958) 564, 570; A. MALNORY, Saint Césaire, évêque d'Arles, Paris 1894, 187-189; G. RAUSCHEN, L'eucharistie et la pénitence durant les six premiers siècles, Paris $1910,156-162,165,187-193,196 ;$ S. HARENT, "La confession. Nouvelles attaques et nouvelle défense": Etudes 80 (1899) 484-485, 601; A. BOUDINHON, "Sur l'histoire de la pénitence. A propos d'un ouvrage récent": Revue d'Histoire et de Littérature Rellgieuses 2(1897) 324325, 329, 335; M. B. CARRA, "Le sacrement de pénitence": Lumière et Vie 13 (1964) 75.

2. Est-il besoin d'ajouter qu'une étude de la pénitence antique n'offre pas seulemen un intérét historique ou archéologique? En raison de leur incidence sur toute la vie du chrétien, les différents systèmes pénitentiels supposent des sensibilités religieuses différentes suivant les époques, ainsi que des techniques pastoralẹs et des thérapeutiques variés. Mieux que l'etude et la comparaison des synthéses théologiques ou philosophiques des pères, une analyse de la situation concrète du pécheur en face de la pénitence, suivant les époques, nous aprend combien les chrétiens, au cours des siècles, sont diffẹrents de nous et combien ils nous ressemblent' (C. VOGEL, Le pécheur et la pénitence dans l'Eglise Ancienne, Paris 1966, 11-12). 
con las decisiones del Concilio de Trento la evolución, se toma un largo tiempo de descanso que llega hasta nuestros días. Merece una atención especial el primer período, el de la Iglesia antigua. Ofrece no pocas dificultades a quienes quisieran constatar, sin salirse de sus límites históricos estrictos, una evolución hacia la benignidad en las formas institucionales penitenciales. Las dificultades son tales que permiten defender, en plena justicia, opiniones dispares y hasta diametralmente opuestas. $\mathrm{Y}$ todas ellas - las más diversas opinionesfundamentadas en argumentos que se consideran históricos. No obstante reina la unanimidad a la hora de fijar cuáles son los hechos fundamentales referentes a las instituciones penitenciales. Hechos que podríamos concretar en los siguientes:

I. La aparición del escrito del Pastor de Hermas.

2. La intervención de un cierto Papa $\mathrm{u}$ obispo que primeramente se había identificado con el Papa Ceferino; después con el Papa Calixto y actualmente algunos historiadores bien documentados atribuyen al obispo Agripino de Cartago ${ }^{3}$.

3. Las actuaciones y decisiones del Papa S. Cornelio y del obispo S. Cipriano.

Advertimos también que, al lado de estos tres hechos, unánimemente considerados como fundamentales, existen otros que suelen citarse como de pasada, sin atribuirles mayor importancia. Bajo el punto de vista, en cambio, que he elegido en estas páginas -evolución de las formas penitenciales hacia la benignidad - estoy convencido de que es necesario tenerlos en cuenta. Me he referido, en otro artículo, fundamental, aunque no exclusivamente, a

-la professio religiosa

-la conversio secreta

- y a la terminología, que en sí encierra un concepto nuevo y un esfuerzo de adaptación, utilizada por algunos escritores eclesiásticos : el (agere poenitentiam» como contrapuesta al (accipere poenitentiam) $)^{4}$.

\footnotetext{
3. La bibliografia fundamental y selecta sobre este punto verse en B. POSCHMANN, Pénitence et onction des malades, Paris 1966, 44-46.

4. Algunas de estas formas penitenciales las estudié en mi anterior articulo, Z. HERRERo, "La penitencia y sus formas. Examen de su evolución histórica": Estudio Agustiniano 6 (1971) 3-32.
} 
Pero la unanimidad de los autores se concreta en la determinación de los tres hechos fundamentales anteriormente citados. No podemos pretender encontrarla cuando se trata de su interpretación y alcance en cuanio a la evolución de las formas penitenciales, y mucho menos cuando se habla de estos otros hechos que califican de secundarios.

\section{Fogonazo impulsante.}

M. H. Lea escribía en 1896 su obra - fundamental para conocer el pensamiento protestante- sobre la confesión ${ }^{5}$. En ella defiende como tesis central que la confesión - tal como se practica actualmente en la Iglesia - es de origen tardío y puramente humano. Trata de probar que, en lo referente al tema penitencial, los teólogos y el papado han falseado la doctrina de Cristo y el pensamiento de la primitiva Iglesia. La confesión responde únicamente a una cierta utilidad práctica: la primitiva Iglesia alejaba, con su severidad, de la comunidad cristiana a los sujetos indignos y hacía reflexionar a los débiles, ya cristianos, sobre la gravedad de sus faltas. También admite una cierta utilidad práctica a la penitencia tarificada en cuanto que las mortificaciones, ayunos, limosnas, en una palabra, en cuanto que las obras de dura satisfacción, que imponía; eran medios y argumentos convincentes para despegarse del pecado.

No obstante, la causa fundamental de la existencia de la confesión la detecta en el exagerado sacerdotalismo que la Iglesia, en su opinión, ha defendido siempre y hasta de forma extremista buscando y ejerciendo un imperio absolutista sobre las personas y sus actos. Actitud que encuentra su expresión máxima en las decisiones del Lateranense IV y del Tridentino estableciendo como obligatoria la confesión en determinadas circunstancias.

Llega a esta conclusión por un proceso de eliminación de todos los demás argumentos que pudieran aducirse en favor de la existencia de la confesión: la satisfacción, impuesta por los pecados y que ordinariamente es insignificante y no proporcionada a la gravedad de

5. M. H. C. LEA, A. Hystory of auricular confession and indulgences in the Latin Church, vol. 1-11: Confession and absolution, Philadelphia 1896. El tercer volumen to dedica a las indulgencias. 
los mismos, no puede justificar la confesión detallada; la absolución tampoco puede justificar dicha institución, porque en vez de comprometer más seriamente al cristiano en la lucha por lograr el desarraigo de sus defectos, le predispone a la recaída precisamente porque otorga demasiado fácilmente el perdón, y sirve de alimento a una mentalidad que cree que el perdón es obra automática del sacramento, como por arte mágica, sin mayores compromisos personales.

De una forma más categórica: defiende que en la Iglesia antigua no existía más que la penitencia pública y que ésta no era sacramental. Consiguientemente, concluye, que en la Iglesia de los primeros tiempos no ha existido el sacramento de la penitencia.

Es natural que unas afirmaciones tan decididas como éstas no dejaran indiferentes a los teólogos católicos. Pronto aparece un número considerable de artículos demostrando la falsedad de las afirmaciones del docto protestante ${ }^{6}$. Todos admiten que Lea, en su ataque a la tesis fundamental católica, manifiesta un esfuerzo considerable por liberarse de los prejuicios protestantes. Actitud que descubren en su reconocimiento sincero de cierta utilidad práctica de la confesión; en el desarrollo total de su estudio, que lo centra y documenta con obras escritas por teólogos católicos; $y$, finalmente, en la ausencia cuidadosa de toda afirmación de mal gusto aue no considere fundamentada científicamente. Hasta reconocen que en Lea no se descubre ninguna actitud personal de mala voluntad y que, en tanto llega a las conclusiones contrarias a la confesión, en cuanto que las considera históricamente fundadas, aunque sean fundamentalmente falsas. Esta actitud global de la obra y persona del conocido protestante dio su fruto positivo en sus oponentes católicos, puesto que los invitaba a mantenerse a igual altura científica en el examen serio y sincero de los documentos históricos. Por otra parte, y como el suyo es un estudio predominantemente histórico, ha conseguido que las res.

6. A. BOUDINHON, "Sur l'histoire de la pénitence. A propos d'un ouvrage récent: Revue d'Histoire et de Littérature Religieuses 2 (1897) 307-344, 494-524; E. VACCANDARD, "Le pouvoir des clefs et la confession sacramentelle. A propos d'un livre récent": Revue du Clergé Français 14 (1898) 192-214; 16 (1898) 421-438; 17 (1899) 142-157; 20 (1899) 337-356 y otros cuatro o cinco artículos más aparecidos en la misma revista; S. HARENT, "La confession. Nouvelles attaques et nouvelle défense": Etudes 80 (1899) 577-605; P. BRUCKER, Etudes, 5 octobre 1897, 96ss; P.CASEY, Notes on a history of auricular confession, Philadelphia 1899. De forma indirecta ya podemos suponer que existen una serie de obras católicas que iré citando. a lo largo del artículo y que hacen referencia al estudio de Lea en varios de sus pasages.. 
puestas de los teólogos católicos de su tiempo estén fuertemente matizadas por la visión histórica, salvando siempre las afirmaciones dogmáticas existentes. Igualmente ha contribuido no poco a que estos artículos, y estudios posteriores, se esfuercen por llegar a una más cuidadosa distinción entre lo esencialmente dogmático y permanente y sus formas de exteriorización, sujetas a una serie de cambios históricos y ambientales del hacerse del pensamiento y de la decisión humanos ${ }^{7}$. De aquí la conclusión a la que, con toda sinceridad, ha llegado uno de estos artículos, que da el título a estas páginas y me interesa hacer notar: "La disciplina penitencial estaba destinada a vivir continuas mitigaciones) ${ }^{8}$.

Boudinhon la defiende con tal convencimiento que la considera la prueba base de la no existencia de la penitencia privada en la Igle-

7. $Y$ es que los historiadores se han convencido de que "Si l'annonce du pardon de Dieu par l'Eglise est une donnée permanente du message évangelique, la maniere de signifier ce pardon a varié, et rien ne parait s'opposer à l'apparition d'une ou plusieurs formes nouvelles" (C. VOGEL, Le pécheur la pénitence au moyen age, París 1969, 910).

Como también se han convencido de que estas variaciones se han producido de la siguiente manera: "Erreur aussi de s'imaginer que la nécessité de soumettre les péchés au jugement de l'Eglise ait entrainé des l'abord les confessions fréquentes qui sont devenues ensuite la conséquence de cette doctrine. Cette traduction en actes de la vérité théorique a été le résultat d'influences multiples, qu'il appartient à l'histoire de démeler. On peut les résumer dans l'action propre de l'Eglise. Ce n'est point qu'elle ait crée élle-même la nécessité absolue du recours au sacrement. Les lois qu'élle a portées sur cette matiére n'ont meme fait peut on dire, que consacrer que generaliser, en les imposants à tous, des usages déjà existants. En ce sens le Decret du Concile de Latran sur la confession annuelle n'a pas été une innovation; pas davantage celui de Trent sur la nécesité, en cas de péché mortel, d'en obtenir le pardon par l'absolution avant de communier: le concile dit en propres termes que la pratique rendue par lui obligatoire était déjà à l'etat de coutume. Mais, coutume o loi posítive, il n'est point douteux que les déterminations ainsi portées par l'Eglise à la loi de Dieu aient puissamment ainsi contribué à en assurer la connaisance et l'observation que nous savons. Jusque là, et pour autant qu'une conduite notoire n'entrainait point l'exclussion des sacrements, chacun restait libre, si meme il songeait, de renvoyer à plus tard le recours au pouvoir des clefs. C'est loissible aujourd'hui encore pour qui veut recevoir autres sacrements que celui de l'Eucharistie; en cas de péché mortel et sauf le précepte de la confession annuelle, on n'est point tenu de s'y disposer par la justification sacramentelle. Jusqu'au Concile de Trente, on ne l'était pas non plus pour la réception de la sainte communion: à plus forte raison, les chrétiens du III et du IV siècle avaient ils la même liberté, et il reste donc á étudier dans quelle mesure ils en usaient ( $P$. GALTIER, "La pénitence en Occident aux derniers siècles de l'antiquité chrétienne": Nouvelle Revue Théologique 56 (1929), 635, 637; A. BOUDINHON, "Sur l'histoire de la pénitence. A propos d'un ouvrage récent": Revue d'Histoire et de Littérature Religleuses 2 (1897), 329, 33. M. B. CARRA, "Le sacrement de pénitence. Aperçu historique": Lumiere et Vie 13(1964)25.

8. A. BOUDINHON, "Sur l'histoire de la pénitence. A propos d'un ouvrage résent": Revue d'Histoire et de Litterature Religieuses 2 (1897) 333.

H. RONDET, "Esquise d'une histoire du Sacrement de pénitence": Nouvelle Revue Theólogique 80 (1958) 572-573: "Costle évolution avalt commencé dès le jour où s'étalent posés de cas spéclaux. Dés les temps de $\mathrm{S}$. Cyprien on s'était demandé comment devaient être réconciliés les agonisants quie n'avaient pas achevé le temps prescrit pour la pénitence et l'on avait résolu le cas dans le sens de l'indulgence (DTC XIV, col. 1148, 1154, 1158-1160). S. Basile, S. Grégoire de 
sia de los primeros tiempos, contra la opinión de no pocos teólogos. Afirma, sin dubitación alguna, que, de haber existido en aquellos tiempos la penitencia privada más o menos como se dig en épocas posteriores, sería inexplicable la existencia y pervivencia a través de los primeros siglos de cualquiera otra forma penitencial más rígida, como lo es la penitencia pública. Y hemos de reconocer que la historia es testigo insobornable de que toda vez que ha surgido una forma penitencial más benigna, la anterior, más exigente, perdía casi totalmente su vitalidad, aun cuando las autoridades se esforzaran por mantenerla en vigor. Más adelante tendremos ocasión de ver los esfuerzos, y también los resultados, de la reforma carolingia por mantener en vigor la forma penitencial antigua o pública, como general, aunque no del todo acertadamente, se la designa ?

Esta conquista de la visión histórica que ayuda a los teólogos católicos a distinguir lo esencial de sus encarnaciones concretas en formas históricas es algo muy importane, cuyos frutos podemos recoger ahora, en nuestros días.

Y dentro de esta visión histórica algunos autores dividen la historia de las formas penitenciales en los dos o tres períodos más visibles de la misma: el período de la Iglesia Antigua con su forma denominada pública; el correspondiente a la penitencia tarifada $\mathrm{y}, \mathrm{fi}$ nalmente, el abarcado por la forma penitencial que nace gradualmente a partir de la reflexión teológica de los siglos XI y XII ${ }^{10}$. Otros, como B. Poschmann prefieren establecer esta otra periodización: la antiguedad cristiana (los seis primeros siglos), época de la penitencia pública; comienzos de la Edad Media, con su pasaje progresivo a la penitencia privada; el tiempo que media entre el fin de la escolás-

Nysse et surtourt $S$. Jean Chrysostome tirèrent les conclusions de cette attitude. S. Augustin fit de meme, bien que gené par les exigences de la discipline. Avec le -temps les formules rigides s'as souplirert. On en a pour témoignage une série de décretes émanées des papes Innocent I (Dz 95) Célestin I (Dz. 111) et S. Leon (Dz. 146-147). On est alors loin des décisions rigoristes du Concile d'Eivire, mais les concessions faites aux mourants vont être généralisées et l'attitude d'un $S$. Césaire d'Arles (Serm. 179, alias 104; R. J. 2233) prépare les ames à accueillir la pénitence privée proprement dite".

9. A. BOUDINHON, a.c. 333. No es momento de pararse sobre la discusión de si existió o no atesde el principio una penitencia privada con todo lo que supondría relatar las diversas posiciones.

10. A. BOUDINHON, a.c. 322; C. VOGEL, Le pécheur et la pénitence au Moyen-Age, París 1969; ID. Le pécheur et la pénitence dans l'Eglise Ancienne, Paris 1969, 9. P. REMY, “Théologie de la pénitence": Lumlère et Vle 13 (1964) 75 la reduce a dos grandes períodos. 
tica y la reforma: elaboración de la docrina penitencial; y el que viene desde el Concilio de Trento hasta nuestros días con ciertos interrogantes que aún no han recibido respuesta después de las decisiones doctrinales del Concilio de Trento ${ }^{11}$.

III Primer periodo, admitiendo la división de B. Poschmann, y su problema fundamental.

El problema que domina la panorámica general de este primer período es el de determinar si existía o no una institución penitencial en los dos primeros siglos. Y dado que nos encontramos con una escasez casi absoluta de obras escritas, y que las pocas existentes abundan en expresiones oscuras, la solución del problema depende en gran parte:

a) de la mentalidad pre-inicial con que se examinen dichas obras y expresiones y b) de la tesis que se defienda en cuanto a la existencia o no existencia de los llamados pecados irremisibles.

a) Mentalidad que llamariamos dogmática.

Esta no sabrá concretar la forma de penitencia existente en los primeros siglos, porque es imposible, pero asegura que ya desde el primer momento la Iglesia ha perdonado los pecados y todos los pecados. Cuando se leen sus argumentaciones, es difícil sustraerse a la impresión de que en ellas se está haciendo una proyección hacia atrás, hacia los primeros siglos de la Iglesia, del pensamiento de la época en que escriben ${ }^{12}$. Solucionan en virtud

\footnotetext{
11. B. POSCHMANN, Pénitence et onction dés malades, París 1966, 13.

12. E. AMANN, "Pénitence": DTC XII, 757: "Nous raisonnons trop, quand nous étudions le passé, d'après les pratiques que nous avons sous les yeux. Dans nos pays de vieille civilisation chrétienne, le baptême des adultes n'est pas qu'une infime exception, et la pratique du sacrement de pénitence est tout naturellement déterminée par cet état de choses. Nous avons quelque peine a nous représenter des communautés primitives oú la très grande masse des baptisés (et ces bap. tisés ne sont pas la très grande messe des chrètiens) n'a reçu le sacrement de l'initiation qu' à tisés ne sont pas la très grande messe des chrètiens) n'a reçu le sacrement de l'initiation qu' à l'age adulte, parfois très avancé, et, pour les périodes anciennes tout au moins, dans des conditions qui supposent une véritable et profonde conversion. Que si l'on "réalise" la situation mo. rale de ces communautés, de celles-là surtuot qui sont petites, tenues bien en main par les autorités, on se rend compte que les nécessités de la pénitence s'y faisaient moins sentir qu' à des époques posterieures. II y a entre l'admission tardive au baptême et la pratique de la pénitence une correlation qui n'a pas toujours été suffisamment perçue, encore que saint Agustin la frasse expressément remarquer".
}

M. B. CARRA; "Le sacrement de pénitence. Aperçu: historique": Lumière et Vie 13 (1964) 20 
de argumentos dogmáticos $\mathrm{y}$, a veces, hasta de documentos no infalibles. Parece que estos escritores ignoran que, por salvar unos documentos que en sí no son infalibles, se oponen, 0 al menos dan la impresión de oponerse, a la misma realidad de los hechos históricos. Como resumen de esta manera de pensar leamos :

"Si la Iglesia, como pretenden algunos historiadores católicos, hubiera excluido del perdón durante siglos a cierta clase de pecadores a pesar de sus buenas disposiciones, entonces o la Iglesia desconocía su deber de conceder la absolución, lo que implicaría un error sobre un punto esencial de la fe; o habría descuidado su deber de cumplimiento, no pudiendo justificarse delante de Dios. Tanto la primera como la segunda de las hipótesis es inadmisible para aquel que admite la institución divina de la Iglesia" ${ }^{13}$.

A veces se afirma también la oposición de ciertas tesis a determinados documentos pontificios, cuando en realidad no existe tal oposición. Stufler, por ejemplo, defiende que las concepciones de algunos historiadores católicos están en flagrante oposi-

\footnotetext{
y nota 15: "La véritable interprétation des faits: Mais on commence de plus en plus s'apercevoir qu'une telle controverse est stérile, car en fait le probléme est mal posé. Inconsciemment, négateurs protestants ou défenseur catholiques de la sacramentalité de la pénitence semblent avoir en commun une conception trop matérielle de l'institution d'un sacrement par le Christ. Ce semble d'ailleurs une tentation constante de l'esprit humain de se représenter la vérité sous une forme simpliste, et notamment d'expliciter tout affirmation historique portanst sur un lointain passé en lui prêtant le visage de nos coutumes actuelles. Entendons-nous parler d'instituer une pratique ayant force de loi? Tout de suite nous songeons à un acte juridique, clair et précis, comme en dresserait un gouvernement contemporain. Nous ne manquons pas de nous gausser d'un tel simplisme: mals en falt nous y succumbons enconre bien que nous le pensons".

Cette ébauche de réponse, dont on ne se dissimule nulleement le caractêre sommaire, voudrait reprendre des principes de solution, que l'on croit très justes, discrètement suggérés ici ou là par E. AMANN au cours de l'article déjà souvent cité; voir en particulier 749-752, 762-763. On pense retrouver des idées analogues, mais beaucoup plus firmement developées et mise en forme, un ouvrage consacré d'ailleurs explicitement à l'étude théologique de la sacramentalité, et non à l'histoire de tel sacrement: c'est le livre si riche et suggestif de E. H. SCHILLEBEECKX, Le Christ, sacrement de la rencontre de Dieu, Paris 1960 . On se référera en particulier au ch. 3 , par. IV..."

H. RONDET, "Esquise d'une histoire du Sacrement de pénitcnce": Nouvelle Revue Théologlque 80 (1958) 573; G. RAUSCHEN, L'eucharistie ef la pénitence durant le six premlers, siècles, Paris 1910, 136ss.

Un buen ejemplo de los defectos aqui indicados podemos encontrarlo en S. HARENT, "La confession. Nouvelles ataques, nouvelle défense": Etudes 80 (1899) 577-605.

13. P. STUFFLER, “La discipline pénitentielle dans l'Eglise occidentales jusqu'au Pape Callixte": Zeitschrift tür Katholische Theologle, 1907, 437; Ch. PESCH, Praelectiones dogmaticae, VII, 21.
} 
ción con la proposición XLVI del Syllabus de Pío X. Y esto no es cierto, puesto que la proposición condena afirmar que "la Iglesia primitiva ha ignorado el poder de la autoridad eclesiástica de reconciliar a los pecadores bautizados" ${ }^{14}$. Y tal afirmación condenada no se encuentra en ninguno de los historiadores católicos. Precisamente ésta es la diferencia existente entre ellos y los protestantes. Mientras los protestantes sostienen que ha habido un tiempo en que la primitiva Iglesia no era consciente de tal poder, los católicos parten del supuesto de que siempre ha sido consciente del poder de perdonar los pecados y todos los pecados; pero que su aplicación práctica ha tenido un desarrollo progresivo y que, por razones de prudencia, a veces y en determinados lugares, ha puesto limitaciones prácticas a su poder, ilimitado de derecho y del cual lo mismo que de su ilimita. ción era consciente, de perdonar los pecados.

b. Mentalidad histórica

Los historiadores, en cambio, insisten en que se dé primacía a lo que diga la realidad de los hechos. No niegan la interpretación dogmática de los mismos, pero exigen que ésta se manten. ga dentro de la realidad histórica sin forzar a los hechos a decir más de lo que hablan por sí mismos. Pohle se expresa de la forma siguiente:

"Quisiéramos insistir en la necesidad de que el teólogo dogmático se incline ante la fuerza de los hechos históricos, aunque éstos le parezcan nuevos, y de entrar en el estudio del espíritu de la Iglesia primitiva con más inteligencia. Nada habría más falso que el juzgar el pasado según el presente. Los tiempos antiguos deben ser comprendidos y juzgados segun ellos mismos. La Iglesia no se ha abstenido del uso del poder de las llaves a causa de una excesiva severidad o incompetencia, sino como consecuencia de situaciones de disciplina eclesiástica y de pedagogía" ${ }^{15}$.

\footnotetext{
14. P. STUFFLER a.c. Zeitschrift für Katholische Theologie, 1908, 536s.

15. Bástenos como prueba la cita del siguiente texto: "Cependant elle n'est pas pour satisfaire tous les théologiens. Visiblement ce qui empêche nombre d'entre eux de l'accepter, c'est une préoccupation dogmatique assez facile à démêler. On craint que le dogme ne soit compromis, si la discipline ne repond pas à l'idée qu'on s'en fait. Plusieurs même se demanderont si le théorie de $M$. FUNCK ne donne pas raison à M. LEA, dont elle semble confirmer la thèse. II importe de nous mettre en garde contre de semblables confussions. II y a entre la thèse de $M$. LEA et la théorie de M. FUNCK un véritable abïme, une différence essentielle. Ce qui est pour l'un une question de dogme n'est pour l'autre qu'une mesure de discipline. Quand M. FUNCK constate (ou prétend constater) que l'Eglise n'accordait pas l'absolution à telle catégorie de pénitents, il n'entend pas
} 
Media, pues, entre ambas mentalidades una concepción distinta de la Iglesia, aunque no se puede decir que sea contraria u opuesta. Más bien diría que son concepciones complementarias. Mientras los guiados por la mentalidad dogmática se centran en la consideración de la penitencia, o forma penitencial, como algo de institución divina no valoran suficientemente el hecho de que esa institución divina ha sido fundada entre hombres, para hombres y entregada a los

nier qu'elle eüt en principe le pouvoir de le faire, il conteste seulement qu'elle ait usé de ce pouvoir à telle époque déterminée. Peut-on dire que M. LEA soit prêt à accepter cette conclusion? S'll en était ainsi, son livre et sa thèse tomberaient du même coup. Mais il est fort à craindre que I'historien de la confession auriculaire ne rejette la thèorie de M. FUNCK aussi bien que ceile de PALMIERI" (M. VACCANDARD, "Le pouvoir des clefs et la confession sacramenteile. IV Caractère sacramentel de la pénitence publique": Revue du Clergé Français 16 (1898) 426.

Les inconveniants de cette généralisation (habla de la aplicación a los sacramentos de la teoría de la materia y la forma) exagérée ont été bien de fois signalés: d'une part, une assimilation forcée entre tous les sacrement, dont on est ténté d'oublier la nature diverse; de l'autre, une fixité aux allures metaphysiques attribués à des institutions dont plusieurs éléments étaient de nature variable, et avaient présenté, de fait plus d'une variation.

,, D'autre part les préoccupations philosiphiques du moyen âge ne laissaient pas beaucoup de place à l'histoire. On ne la connaissait guère et, ce qu'on en connaissait, on l'interprétait avec une naïve partialité dont il subsiste encore bien des traces dans les ouvrages de la théologie contemporaine: on ne pouvait admettre que des conclusions si logiquement déduites de principes tenus pour inattaquables ne fussent pas également certaines. On appliqua donc le raisonnement déductif aux institutions ecclésiastiques, telles qu'on les vait alors sous les yeux sans se preoccuper du passé. De là une tentation à laquelle on ne pouvait guère échapper de transformer en nécessité absolue ce quî n'était qu'une nécessité conditionneile, c,est à dire Ǵlant donné la pratique en vigueur. Cola s'est produit tout particulièrement pour la pénitence dont la théologie est basée sur la pratique des XII et XIII siècle. Certaines de ces deductions ont abouti à des conséquences pratiques, à des règles três légitimement acceptées et imposées pra l'Eglise; l'exemple le plus frappant est sans doute l'emploi, devenu nécessaire des formes d'absolution impérative ou indicative et l'exclusion progressive des anciennes formules déprécatives; changement qui n'implique d'ailleurs aucune modification dans le dogme. Par contre certaines déductionj laborieusement tirées de la théorie de la matière et de la forme, n'ont pu prévaloir conire la pratique; c'est ainsi par exemple, qu'on a toujours donné l'absolution aux malades privés de connaissance bien qu'ils fussent dans l'impossibilité de faire aucun acte sensible apte à devenir la matière du sacrement. Au reste, on ne pouvait pousser bien loin l'application de la théorie, tellement la nature spéciale du sacrament y faissait obstacle. On sait d'ailleurs que le concile de Trente, I. c. a désigné les actes du pénitent comme "quasi materia" du sacrement" (A. BOUDINHON, "Sur l'histoire de la pénitence. A propos d'un ouvrage récent": Revue du Clergé Français 2 (1897) 320-321; P. de SMEDT, Principes de la critique historique, 1883, 232. H. RONDET; "Esquise d'une histoire du sacrement de pónitence": Nouvelle Revue Théologique 80 (1958) 167-168, 573; GALTIER, "La penitence en Occident aux derniers siécles de l'antiquité chétienne": Nouvalle Revue Theologique 56 (1929) 646-647, 633; E. VACANDARD, "Le pouvoir des clefs et la confession sacramentelle": Revue du Clergé Françals 14 (1898) 196, 428-429; 16 (1898) 5; 17 (1899) 156-157.

"Le P. BONACCORSI appuei les réserves de Rauschen; il rapelle que le principe théologique selon lequel l'Eglise peut selon les cas et les temps administrer la pénitence avec plus de sévérité ou plus d'indulgence, est un principe indiscutable et qu'il a été défendu "par les grandes théologiens français du XVII siècle qui ont traité de la question de la pénitence", à commencer par PETAU lequel était pour le moins aussi sûr que le P. Stuffler. Pareil jugement chez J. Bellamy, La theologie catholique au XIX siecle, Paris 1904, 113-121; nota del traductor de G. RAUSCHEN; L'eucharistie et la pénitence durant les six premiers siècles de l'Eglise, Paris 1910, 137 not. 2) 
hombres en cuanto a sus formas de exteriorización; los defensores de la mentalidad histórica insisten precisamente en este elemento humano que admite y está sometido a la evolución, como todos los demás elementos humanos. Y esta es la razón por la cual las llamábamos más bien opiniones complementarias entre sí, y por la que me inclino por la corriente de los historiadores ${ }^{16}$.

c. Posición diversa frente al interrogante sobre la existencia de los pecados irremisibles.

El interrogante, con la divergente respuesta dada por los autores al problema de la existencia o no existencia de los pecados irremisibles, en la primitiva Iglesia, es otro obstáculo a la fácil compresión y al esquema homogéneo que nos facilitaría seguir el camino recorrido por las formas penitenciales hacia la benignidad. Sobre el tema a que nos referimos en este apartado podemos distinguir estas tres opiniones:

\section{Opinión protestante}

Ya hemos expuesto anteriormente la opinión expuesta por M.H. Lea en su obra. En la actualidad, cuando se trata de este tema desde el punto de vista protestante, suele acudirse a HARNACK ${ }^{17}$. Autor que, partiendo del presupuesto de que la primitiva Iglesia se consideraba como comunidad de santos, afirma que no existía institución alguna tendente a la reparación de la obra bautismal, destruida por el pecado. El perdón del pecado se le reservaba a solo Dios.

\footnotetext{
16. POHLE, Lehrbuch der Dogmatik, III, 1905, 483; E. VACCANDARD, a.c. Revue du Clergé Françals 16 (1898) 5, S. HARENT, "La confession Nouvelles ataques, nouvelle défense": Etudes 80 (1899) 577-605 se muestra contrario al método histórico; P. GALTIER admite dicho método como complemento, aunque expresa su temor de que se le conceda excesivo valor y le pone ciertos reparos, P. GALTIER, "La pénitence en Occident aux derniers siècles de l'antiquité chétienne": Nouvelle Revue Théologique 29 (1956) 633, 643ss., 637, 649 not. 1.

17. Toutes ces questions, et d'autres qui y sont connexes, se doivent et se peuvent étudier indépendement de toute préoccupation doctrinale. La solution en appartient a l'histoire, et l'on peut seulement demander à l'historien de ser garder des conclusions précipitées. La différence du présent au passé, qui es incontestable, ne doit point lui en faire exclure trop aisément la continuité possible. Rares dans toutes les societés qui se developpent, les commencement brusques et les innovations absolues le sont surtout dans l'Eglise. Bien des usages. et des institutions n'y ont reçu qu'après coup leur forme et leur désignation définitives. C'est vrai, en general, de tout ce qui touche à l'administration des sacrements ce l'est, en particulier, de sacrements qui, comme le mariage et la pénitence au lieu de consister en un rite matériel aux contours nécessairement fixes et bien dessinés, se réduissent à un ensemble d'actes humarns suceptibles des moyens a ex-
} 
En conjunto la práctica respondía a este pensamiento básico. No excluye, sin embargo, que en ciertos casos se consiguiera el perdón de ciertos pecados graves mediante una confesión ante el poder $\mathrm{y}$, sobre todo, por efecto del Espíritu cuyas manifestaciones extraordinarias tenían lugar a través de los mártires, confesores y profetas. Pero no existía institución alguna como tal.

Así, pues, estaban excluidos definitivamente de la Iglesia - Iglesia de los santos- quienes incurrían en los pecados de apostasía, de adulterio y de homicidio. $Y$ esto no sólo por razones prudenciales, sino por principio teórico y convicción. Así mantenía la separación y la distinción entre la Iglesia y el resto del mundo, entre los pertenecientes a la comunidad de los santos, los cristianos, y los paganos.

Era una línea divisoria perceptible a los sentidos. Más tarde Hermas extenderá la penitencia a una serie de pecados mediante la (exomologesis), pero una sola vez. Con esta limitación a "una sola vez) aún se mantenía una cierta división entre los cristianos y los no cristianos, entre los pertenecientes a la comunidad de los santos y los no pertenecientes a la misma. Por ello los defensores de la idea de la comunidad de los santos en todo su rigor primitivo aún se contienen y no exteriorizan reacción alguna. Pero cuando el edicto, llamado de Calixto, abre la puerta a los (moechi), se considera que lesiona notablemente la norma fundamental que dividía a los cristianos de los no cristianos y surge la polémica abierta que, con el tiempo, degenerará en cisma, cuando la ampliación se extienda también a los apóstatas.

Así, pues, la Iglesia primitiva no sólo no poseía institución penitencial alguna, sino que tampoco era consciente de su poder de perdonar los pecados. Adquiere esta conciencia, por vez primera, con la publicación del llamado edicto de Calixto.

Ese no ser ni siquiera consciente de su poder de perdonar los

\footnotetext{
pression les plus variés. Aussi, à vouloir en rechercher les manifestations premièrs, importe-t-il de ne pas regarder uniquement aux formules et aux dénominations plus récentes qu'ont pu en recevoir les divers éléments. Avant d'etre ainsi appellés, définis, catalogués, et sans meme etre encore l'objet d'aucune appelation fixe, n'auraient-ils point existé déjà?

Questions, disons-nous; et les poser ne veut point dire que nous y prevoyions nécessairement une réponse affirmative. Tout au moins ne pensons nous pas que cette réponse doive etre la meme pour toutes les Eglises et pour toutes les époques de la période envisagée. Mais nous croyons qu'il appartient à l'historien de les examiner et que luj-meme aurait tort, parce qu'aucun intéret doctrinal ne s'y trouve engagé, d'y passer autre trop rapidement" (P. GALTIER, "La pénitence en Occident aux derniers siècles de l'antiquitéschrétienne": Nouvelle Revue Théologique 56 (1929) 637.
} 
pecados en la primitiva Iglesia, es lo que fundamentalmente distingue la opinión protestante de la de no pocos historiadores católicos. Estos defienden que la Iglesia ha sido consciente, desde el primer momento, de su poder ilimitado de perdonar los pecados pero que, por razones prácticas y de prudencia, no lo ha hecho efectivo desde el principio ${ }^{18}$.

Algunos autores han rechazado esta opinión como radicalmente opuesta al pensamiento católico ${ }^{19}$. No es mi intención aprobarla, pero pienso que la sinceridad nos invita a tener en cuenta estas afir. maciones del teólogo católico M. B. Carra de Vaux Saint-Cyr:

"¿Acaso no provienen de aquí las oscuridades que acompañan a la historia de la penitencia del siglo II y buena parte del III? Se $d u d a$ sobre puntos acerca de los cuales la voluntad de Cristo parece manifestada con una insistencia y claridad menores. $Y$ con razón: porque Cristo ciertamente manda perdonar "setenta veces siete" (Mat. 18,22), pero ¿el bautismo? ...no significa la ruptura total con el pecado: " ¿ $\mathrm{Si}$ hemos muerto al pecado cómo podemos continuar viviendo en él"? (Rom. 6,2).

Il faudra un certaien temps pour que la conscience ecclésiale prenne définitivement de l'assurance quant à la teneur et à la portée de l'héritage recu du Christ par l'intermédiaire des apôtres sur ce point précis.

"Podemos observar, además, que no es claro el sentido mismo de esta duda. ¿Duda la Iglesia del poder de perdonar ella misma los pecados cometidos después del bautismo: o más bien, se niega a usar dicho poder por considerarlo inoportuno? Hemos de admitir que los pocos documentos de la época que existen, no se preocupan lo más mínimo de esta distinción. Probablemente ni siquiera la sospechan. Y, sin embargo, la cuestión existe realmente..."

\section{Opinión de Petavio}

Petavio, en realidad, estudió el tema en tres lugares diferentes de sus obras. Ni siquiera en tres obras de un mismo autor descubrimos una tesis permanente y defendida uniformemente. Ello puede ayudarnos a hacernos una idea sobre la dificultad de llegar a una conclusión en este tema.

A Petavio se le considera el primer defensor de la existencia de los pecados irremisibles en la primitiva Iglesia. Se negaba el perdón

18. A. HARNACK, Lehrbuch der Dogmengeschichte, 4.a edic., Tübingen 1909, 439-444

19. Algunas indicaciones hice en la nota 15 de este artículo. 
a los adúlteros, apóstatas y homicidas. Tal era la práctica hasta la entrada en vigor del llamado Edicto de Calixto, que rompe con dicha práctica y por ello supone un paso importantísimo en el caminar hacia la benignidad de la institución penitencial. Así pensaba en 1922 en su De poenitentiae vetere in Ecclesia ratione. Diatriba ex Epiphanianis anidmaversionibus ad haeresis LIX quae est Novatianorum... excerpa ${ }^{20}$.

En 1633, al escribir su De poenitentia et reconciliatione veteris Ecclesiae moribus recepta..., centra su atención y reflexiona sobre el canon 13 del Concilio de Nicea que concedía la penitencia, en caso de muerte, a los culpables de los pecados anteriormente citados. En esa obra mitiga su afirmación del 1622 y ya no defiende que la existencia de los pecados irremisibles sea una práctica universal de la Iglesia católica. Al menos los que se encontraban en peligro de muerte no eran excluidos de la penitencia en todas las iglesias, aunque sí en algunas ${ }^{21}$.

Finalmente en 1643-1644 escribe su De poenitentia publica et praeparatione ad communionem ${ }^{22}$. Sigue defendiendo la tesis de r633 pero con algunas precauciones más y sin tanta seguridad como en la obra anterior.

A Petavio le siguió J. Sirmond ${ }^{23}$. Y en nuestros días ha habido defensores de su opinión y concretamente los estudios de Funck han tenido gran influjo. El mismo ha corregido también su tesis en diversas ocasiones. Su último pensamiento era que la Iglesia había sido consciente desde los comienzos, de su poder ilimitado de perdonar todos los pecados; pero que en la práctica algunas iglesias locales, diríamos hoy ${ }^{24}$, también desde su origen limitaron el ejercicio de dicho poder de tal manera que excluían del perdón, por razones de discipli-

20. Vid. Las notas $13,14,15,16$.

21. M. B. CARRA, "Le sacrement le pénitence: aperçu historique": Lumière thie 13 (1964) 23, 13, 14, 23; A. BOUDINHON, "Sur I'histoire de la pénitence. A propros d'un ouvrage récent": Revue d'Histoire et de Littérature Rẹligieuses 2 (1897) 337-338; P. BATIFFOL, Etudes d'hlstoire positive. Tere Serie. La discipline de l'arcane. Les origines de la pénitence, París 1920, 126-127.

22. D. PETAVII, Opus de theologicls dogmatibus, VI, Venetiis 1757: De poenitentia vetere in Ecclesia ratione dlatriba ex Epiphanlianis animadversionibus ad haeresim L.IX, quae est Novatianorum excerpta (1622) .c. II, p. 212.

Me refiero a la edición de Venecia por la comodidad que ofrece a la hora de compulsar las principates publicaciones de Petavio sobre la penitencia.

23. De poenltentia et reconciliatione veteris Ecclesiae motibus recepta diatrlba ex notis synesium eruta, 1933, c. IV, p. 314 A.

24. De poenitentta publica et praeparatione ad communionem, 1644, lib. II, c. II, p. 244B-245A Vid. ESSER, Katholle 1 (1908) 97. 
na y edificación, algunos pecados. Considera las obras de Tertuliano como testimonio interesante de dicho rigor limitante y sostiene que dicho rigor es introducido en la iglesia de Roma mediante el escrito del Pastor de Hermas. El Pastor, pues, en su opinión es representante de la corriente rígida. Lógicamente el Edicto apelado de Calixto representa, en su estructura mental la ruptura con la práctica penitencial existente en el momento de su entrada en vigor, y el primer paso de retorno a los primeros tiempos en los que la Iglesia defendía y aplicaba en la práctica su poder ilimitado de perdonar los pecados ${ }^{25}$.

\section{Opinión de Morín}

Poco después de conocida la interpretación de Petavio surgió otra interpretación del Edicto de Calixto y de los escritos de Tertuliano. La exponía Morín en su Commentarius historicus de discipli. na in administratione sacramenti poenitentiae. Opina que la diferencia entre cristianos y montanistas no consistía en que los primeros admitieran a la penitencia a los culpables de apostasía, adulterio y homicidio y los montanistas no. Ambos admitían a penitencia a todos. Pero mientras los cristianos les concedian también la reconciliación con la Iglesia, los montanistas se la negaban a cuantos hubieran incurrido en cualquiera de esos tres pecados ${ }^{26}$.

A Morín le había precedido en la defensa de esta tesis Gabriel de Ausbique y le siguieron Noel Alexandre y el cardenal Orsi ${ }^{27}$. Y en nuestros días esta opinión ha ido perfilándose progresivamente, defendiendo que el Edicto de Calixto no estaba destinado a romper una práctica rígida que pudiera existir en su tiempo, sino a dar consistencia a la corriente benigna, ya existente en algunas iglesias locales que se opusieron al montanismo. No habría significado, pues, el nacimiento de una nueva orientación, sino la consolidación de una tendencia ya existente ${ }^{28}$.

\footnotetext{
25. J. SIRMOND, Historia poenitentiae publicae, París 1651.

26. Véase nota 1.

27. I. MORINUS, Commentarius historicus de disciplina in administratione sacramenti poenitetiae, Venetiis 1702 , lic. V, 6 , p. $177 \mathrm{~B}$.

28. G. de AUSBIQUE, De veteribus Ecclesiae ritibus observationum libri II, Paris 1623; N. ALEXANDRE, Historia ecclesiastica, Paris 1699.
} 
IV. Existencia de ambas corrientes, rigida y benigna, durante este primer periodo.

A. Aclaración: Cualquiera de las dos tesis que pudiéramos llamar extremistas, bien sea la defendida por los protestantes bien la sostenida por Petavio y sus seguidores, se prestaria admirablemente para probrar la idea que pretendo asentar en este artículo: el afianzarse progresivo de la tendencia hacia la benignidad en las formas penitenciales externas de manifestar la penitencia interna del corazón. Los pasos de la mitigación podrían escalonarse sucesivamente así: I) Consciencia de la Iglesia de su poder ilimitado de perdonar los pecados, pero sin llegar a una aplicación práctica. 2) Afirmación tímida de Hermas de que existe en la práctica - el derecho se encarna en una forma visible- una penitencia posible después del bautismo, aunque sólo sea de forma excepcional 'una sola vez en la vida'-, y que se extendería a todos los pecados, sin distinción entre remisibles e irremisibles, según algunos autores; o excluyendo los irremisibles, según otros autores. 3) Afianzamiento del pensamiento que defiende la posibilidad de la penitencia postbautismal con las obras del Tertuliano católico. 4) Afirmación oficial de dicha doctrina en el Edicto de Calixto y primera ampliación de la aplicación práctica del derecho ilimitado de perdonar admitiendo a los (moechi). 5) Finalmente ampliación de dicho poder a los apóstatas a consecuencia de los estragos causados por las persecuciones, especialmente por la de Decio; sin atreverse a determinar en qué momento se admitió también al perdón a los culpables de homicidio ${ }^{29}$.

Pero, por tentadora que sea esta interpretación de la historia, no podemos olvidar una segunda opinión defendida por historiadores de

29. LOOFS, Guide pour I'histoire du dogma, IV, 1906, 206, y en la p. 208 escribe: "Callixte adopte á coup sâr la conception presque universelle. II n'était pas le premier à tirer de cette pratique les consequences dogmatiques, ni à comparer l'Eglise avec l'arche de Noé, remplie d' animaux purs et impurs, tout ensemble".

MONCEAUX, Histoire littéraire de l'Afrique chrétienne, I, 1906, 432ss:

ESSER, "L'edit d'indulgence du pape Callixte": Theologische Quartalschrift (1906) 541-568 Katholik 2 (1907) 184-205, 297-309; 1 (1908) 12-28. 113; P. STUFLER, "La controverse sur l'edit du Pape Callixte": Zeitschrift für Kathollsche Theologie (1908) 1-42; POHLE, Lehrbuch der Dogmatik, III, 1905, 401-403; P. STUFLER, "La discipline pénitentielle dans l'Eglise occidentale jusqu'au pape Callixte": Zeltschrifł für katholische Theologie (1907) 437-473; (1908) 536; E. VACCANDARD, "Le pouvoir des clefs et la confession sacramentelle. A propos d'un livre récent": Revue du Clergé Français 16 (1898) 426-432. 
reconocido renombre. Estos parten de la convicción clara, fruto de sus investigaciones, de que en la Iglesia ha existido, ya desde sus comienzos, no solamente la conciencia clara de su poder de perdonar todos los pecados, sino también una práctica penitencial que los abarcaba a todos, sin distinción de ningún género. Jamás habría existido en la Iglesia el problema de los pecados irremisibles, ni de hecho ni de derecho. Esto les permite afirmar que el escrito de Hermas no ha significado "revolución" alguna en la primitiva Iglesia ${ }^{30}$. Ya he indicado anteriormente que ciertos autores hasta le catalogan entre los defensores de la rigidez ${ }^{31}$. Y otro tanto afirman con referencia al Edicto de Calixto, y a las intervenciones del Papa S. Cornelio y de S. Cipriano $^{32}$.

Esta segunda visión de la historia de la penitencia, a primera vista, parece destruir mi tesis. No creo que podamos llegar a esta conclusión. No es mi intención determinar cuál de las dos interpretaciones de la historia está en posesión de la verdad, ni tampoco precisar lo que haya de veracidad en cada una de ellas. Tanto unos como otros - grandes investigadores todos ellos- han deducido sus conclusiones basadas en una abundancia impresionante de argumentos, examen interno de la obra, crítica textual, ambiente de las respectivas épocas y de las posteriores etc.

Pero es que además no considero necesario esforzarse en precisar estas cuestiones, porque ellos mismos parece que intentan moderar la importancia que la primera interpretación de la historia concede a los hechos vistos como prueba de la mitigación. Su finalidad no es negar de forma radical la mitigación creciente experimentada en el campo práctico de las formas penitenciales externas, sino rebajar un poco, diríamos, los grados de mitigación. Nos basta, pues, con que admitan una cierta mitigación aunque ella fuera de grado inferior.

30. C. VOGEL, Le pécheur et la pénitence dans l'Eglise Ancienne, Paris 1966, 24. P. GALTIER, "La pénitence en Occident aux derniers siècles de l'antiquité chrétienne": Nouvelle Revue Théologique 56 (1929) 631; M. B. CARRA, "Le sacrement de pénitence. Aperçu historiquẹ": Lumière et Vie 13 (1964) 10, 13, 17-18. 
Hasta podríamos admitir, si ello fuera necesario y se probara apodípticamente, que la primitiva Iglesia no sólo tenía conciencia de su poder de perdonar los pecados, sino que también creó ciertas formas de hacerlo práctico y eficaz sin limitación de ningún género. Pero ni la concesión de esta hipótesis destruye la afirmación de que las formas de exteriorizar la penitencia han recorrido un caminar de constantes mitigaciones. Porque lo que jamás podrá negarse, a la luz de los documentos históricos, es que cada vez que alguna de esas tres formas de pecados más importantes para la historia de la penitencia antigua - adulterio, apostasía, homicidio- dejaban de tener una existencia esporádica y pasaban a ser habituales, en cada uno de esos momentos surgía en el seno de la Iglesia una fuerte tensión entre los partidarios de la benignidad y los inclinados al rigorismo, sean estos montanistas, novacianos u obispos o estudiosos que procuraron mantenerse dentro de la Iglesia ${ }^{33}$. Creo que las actuales discusiones en torno a las cuestiones matrimoniales pueden darnos una idea bastante aproximada del enfrentamiento de corrientes que entonces se produjeron acerca del tema penitencial. Más aún, basados en documentos, podemos afirmar que dicha tensión entre las dos orientaciones sobre los tres pecados calificados de irremisibles se repetirá en siglos posteriores, siglos $\mathrm{V}$ y VI, cuando las incursiones de los bárbaros y la esclavitud de los cristianos caídos en poder de otros pueblos reproduzcan unas situaciones análogas a las vividas en los tiempos de la publicación del Edicto de Calixto, de S. Cornelio, S. Cipriano etc.

La tensión a la que me estoy refiriendo en este tema emerge con tal vigor de la literatura de la primitiva Iglesia que, caso de plantearse la disyuntiva de tener que negar esta tensión o una interpretación concreta de la historia que no admitiera dicha tensión, me obligaría a rechazar como errónea una tal interpretación. Tal es la fuerza de la constatación de la tesis defendida en los escritos de este primer período de la historia de las formas penitenciales ${ }^{34}$. El mis-

33. Ya lo iremos viendo a medida que estudiemos cada caso en esta serie de artículos que me propongo dar a conocer sobre la historia de la penitencia en cuanto a sus formas externas.

34. E. VACCANDARD, "Le pouvoir des clefs et la confessión sacramentelle. A propos d'un ouvrage récent": Revue du Clergé Français 16 (1898) 426; H. RONDET, "Esquise d'un histoire du sacrement de pénitence": Nouvelle Revue Théologique 80 (1968) 566-568 y nota 20, 572-573; S. HARENT, "La confession. Nouvelles attaques et nouvelle défense": Etudes 80 (1899) 500 ; P. BATIFFOL, "Etudes d'histoire positive. 1ere serie. La disclplina de l'arcane. Les origines de la pénitence, Pariis 1920, XVIII-XIX. 
mo D'Ales, uno de los mejor documentados defensores de esta opinión, titula su capítulo sobre el homicidio: "fin del rigorismo penitencial). Razón por la que no creó violentar su pensamiento al darle esta interpretación ${ }^{35}$.

He hecho todas estas concesiones con el afán de ser lo más objetivo posible, escuchando el lenguaje de los sucesos históricos y prohibiéndome toda argumentación a priori. Desde este ángulo de enfoque elegido, lo más razonable es el admitir que la primitiva Iglesia era consciente - aunque sólo en algunas de sus iglesias locales- del poder ilimitado de perdonar todos los pecados, pero que también conocía su posibilidad de no hacerlo efectivo de una manera total y absoluta. Tenía poder, pero se había encomendado a su prudencia el determinar cuándo y cómo llevarlo a la práctica, cual sabia deducción de los principios de su espíritu en combinación con las circunstancias concretas en que se movía cada cristiandad local ${ }^{36}$. No pocos teólogos se sienten a disgusto con esta interpretación y quisieran arrancarla de

36. M. B. CARRA, "Le sacrement de pénitence. Aperçu historique: Lumière et Vie 13 (1964) 15-16; 20-24; P. BATIFFOL, Etudes d'histoire positive. 1ére sẹrie. La discipline de l'arcane. Les origenes de la pénitence, París 1920, 85, 142-144.

No hemos de tener gran dificultad en admitir esta afirmación, si partimos de que la primitiva Iglesia no ha pensado, ni podía pensar, sistemáticamente, sino que se aplicaba a solucionar los casos concretos cada vez que se le presentaban con matizaciones particulares:

"Cette évolution avait commencée dés le jour oú s'étaient possés des cas speciaux. Dès les temps de $S$. Cyprien, on s'était demandé comment devaient etre reconciliés les agonisants qui n'avaient pas achevé le temps prescrit pour la pénitence et l'on avait résolu le cas dans le sens de l'indulgence..." (H. RONDET, "Esquise d'une histoire du sacrement de pénitence": Nouvelle Revue Théologique 80 (1958) 572.

"Une génération à peine aprês Tertullien la question de la Pénitence devint plus actuelle que jamais, à la suite de la grande apostasie suscitée lors de la persécution de Dèce. Le souci de ramener à l'Eglise les égarés obligea à ériger des principes uniformes pour les exigences pénitentielles, qui satisfassent aussi bien la sévérité de la discipline que les besoins pratiques" (B. POSCHMANN, Pénitence onctions des malades, Paris 1966, 54). $Y$ es interesante la toma de posición de POSCHMANN ante el reproche de inconsecuencia que constantemente hace Tertuliano, en el de Pudicitia, a los cristianos porque conceden la paz a los "moechi" y se la niegan a los apóstatas. Rechazan como simplista la creencia de que Tertuliano violente la realidad de los hechos. Admite las afirmaciones de Tertuliano, aunque circunscribiéndolas un poco, de que en aquellos momentos no se concedía la reconciliación a los apóstatas y homicidas sencillamente porque no se habían planteado aún como casos que atrajeran especialmente la atención de las primitivas comunidades cristianas (B. POSCHMANN, Pénitence et onction des malades, Paris 1966, 46-47). 
raíz. Algunos de ellos se conforman con afirmar que no es (loisible» esta posición; mientras que otros, si no se atreven a tildarla abiertamente de herética, sí que creen que el defenderla equivale a decir que la Iglesia ha errado en un punto esencial de la fe o, al menos, que se ha olvidado de su deber en un grado tal que no podría tener justificación ante Dios ${ }^{37}$.

No obstante si tenemos en cuenta I) la penuria de documentos, 2) su oscuridad, tal que dejan amplia libertad de interpretación y 3) si no queremos arrancar a los hechos históricos más palabras que las que ellos mismos encierran, hemos de concluir que, a partir de un cierto momento de la historia antigua, no podemos afirmar nada sobre la época anterior. Concretamente es difícil probar la existencia de dos fuertes corrientes contrarias; inclinada hacia la benignidad la una, y hacia la rigidez la otra. Esto quiere decir que no pretendo sacar conclusiones referentes a la época anterior al escrito de Hermas ni a la posterior a S. Cipriano y S. Cornelio. Los escritos conocidos de es-

Por tanto en la primitiva Iglesia no podemos buscar un pensamiento sistemático, sino que procedía solucionando casos concretos y a medida que se presentaban. Este seria el primer dato que no podemos perder de vista.

Otro dato importante que tampoco podemos olvidar es el de la notable independencia de que gozaba cada obispo para actuar en su propia iglesia. vid. HERAUSGEBER, "Zur Geschichte der pönitentialbücher": Archiv für katholische kirchenrecht 30 (1873) 207-208; C. VOGEL, Le pécheur et la penitence dans l'Eglise Ancienne, París 1966, 24-25. Ni podemos olvidar, como estudiaré en otro artículo, que la evolución en el tema penitencial se hace bajo el influjo tanto de necesidades internas como bajo la presión de circunstancias externas, que podían ser diversas en cada iglesia particular. Se constata claramente en cuanto a la transición de la penitencia pública a la privada, por lo cual parece bastante razonable admitirlo en cuanto a estos primeros siglos (H. RONDET, "Esquisse d'une histoire du sacrement de pénitence": Nouvelle Revue Théologique 80 (1958) 573. Finalmente recuerdo el planteamiento de la tesis hecha desde las primeras páginas de este artículo: no se interroga sobre la posibilidad o no de conceder la reconciliación, sino sobre la conveniencia o no de concederla. Se da por supuesta la posibilidad de otorgar la reconciliación, pero su aplicación práctica es cuestión de prudencia. Esto concede ya una gran flexibilidad en la aplicación del poder de perdonar. $Y$ se aumenta dicha flexibilidad dado que su aplicación depende en buena parte de la prudencia de los rectores de las iglesias particulares y de las circunstancias concretas en que se encuentran tanto quienes han de decidir como aquellos sobre los que recaerá la decisión. Esto se descubre fácilmente en la solución dada por $\mathrm{S}$. Cipriano de la Iglesia de Africa en el tema de los apóstatas que precede a la dada por la iglesia de Roma. $Y$ dicho pensamiento es confirmado también por los oráculos de Montano: La Iglesia puede conceder la reconciliación a todos, pero no es conveniente (C. VOGEL, Le pécheur et la péniftence dans l'Eglise Ancienne, París 1966, 24ss.)

37. D'ALES, L'edit de Calliste, París 1914, 113, a quien se refiere P.'BATIFFOL, Etudes d' histoire positive. 1ère serie. La disciplina de l'arcane. Les origines de la pénitence, París 1920 XVII-XIX; E. VACCANDARD, Le pouvoir des clefs et la confession sacramentelle. A propos d'un livre récent": Revue du Clergé Français 16 (1898) 426; S. HARENT, "La confession. Nouvelles attaques et nouvelle défense": Etudes 80 (1899) 500 . 
tos autores atestiguan la existencia de ambas corrientes en sus respectivas épocas. Sobre la época anterior a Hermas solamente son admisibles conjeturas. Tan falta de pruebas está la afirmación de que dominaba la corriente benigna, como la de que la corriente rígida se había impuesto como norma práctica con la creación de los tres pecados irremisibles.

Aún quisiera precisar más mi afirmación. La corriente rígida existía ya y tenía su influjo en tiempo de Hermas, pero no lograba imponerse en todas y en cada una de las iglesias particulares, siendo distinto su influjo y poderío en cada una de ellas. Es decir, que el rigorismo no era una práctica universal, unívoca y común en toda la Iglesia. Sencillamente logró imponerse en algunas iglesias particulares la corriente rígida, mientras en otras de estas iglesias particulares era más fuerte la benigna. Además los acontecimientos históricos nos prueban que, tanto en las iglesias dominadas por la corriente benigna como en las dominadas por la tendencia rígida, se encontraba un grupo fuerte de oposición que defendía el pensamiento contrario a la

38. Ya hice referencia a este punto en la nota 36 . Esta nota 38 y la 36 se complementan mutuamente.

"Le P. De SMEDT, dont on ne saurait contester la science et l'orthodoxie, posait, il y a dix ans, la règle suivante qui nous parait souverainement sage: "Je ne m'appuierait jamais sur les assertions générales des pères du IV siècle, et à plus forte raison des temps posterieuis, par rapport aux institutions primitives. Les pères sont des témoins autorisés de la tradition dogmatique pour le tempset la contrée où ils vivent, mais ils n'ont, comme tels, aucune autorité spéciale quant à la tradition historique, et j'ai rapporté ailleurs (Principes de la critlque historiquee 1883,232 ) des exemples frappants pour montrer qu'on ne peut avoir une confiance aveugle dans leurs affirmations même les plus péremptoires en matière d'érudition" (Revue des Questiones Historiques 2 (1888) 331 cit. por E. VACCANDARD "Le pouvoir des clefs et la confession sacramentelle. Caractères sacramentel de la pénitence publique": Revue du Clergé Françals 16 (1898) 427 que continua: "D'après ce principe il est peu sûr d'invoquer la discipline pénitentielle du IV slècle en témoinage de ce qui se passait durant les trois premiers". Vid. E. VACCANDARD, 14 (1898) 206-207.

"Quelque incomplets et insuffisants dans le détail que soient les témoignages étudiés jusqu' ici, ils permettent néamoins de constater le caractère universel des principes régissant la Pénitence. Pour Jeur application cependant, une certaine latitude était laissée à l'appretiation des supérieures eccésiaspiques. Deux questions sẹ posaient: 1) quel pécheurs peuvent-on admettre à la pénitence; 2) la pénitence à accomplir était-elle suffisante pour justifier la réconciliation? On pouvait y répondre de façon sêvère ou clemente. D'une part, les nécessités partorales, augmentant sans cesse avec l'accroissement des communautés, poussaient à une attitude bienveillante envers les pécheurs, tandis qu'au contraire le souci de la sainteté chrétienne et la rigueur de la discipline ecclésiastique exigeaient une conduite stricte" (B. POSCHMANN, Pénitence et onction des malades, París 1966, 41).

La independencia de este estilo se hace visible especialmente entre la Iglesia de Occidente y la de Oriente (GALTIER, a.c. 639-640).

La misma crítica que hace Poschmann a Tertuliano cuando en su ataque a la Iglesia parece dar a esa expresión "ab ecclesiis" el sentido de que en toda la lglesia se admitía a lọs 
corriente que había logrado triunfar por su propia fuerza ${ }^{38}$. Este dualismo es el que, precisamente, va a permitirnos constatar cómo la corriente benigna, con gran esfuerzo, va introduciendo sus mitigaciones cada vez más amplias y significativas. Y este caminar hacia la benignidad, realizado en medio del trabajo de una reflexión apoyada en la fundamentación de los principios teológicos y conscientes de las necesidades pastorales de su tiempo, puede decir mucho a los hombres que vivan y reflexionen sobre los actuales problemas pastorales en torno a la confesión.

B. Existencia de ambas corrientes, hacia la benignidad y hacia la rigidez.

Pueden aducirse en favor de la existencia tanto de la una como de la otra corriente exactamente los mismos argumentos. No puede dudarse que, a cada argumento aducido en favor de una sentencia, el historiador que esté convencido de la sentencia contraria, puede aducir un contra-argumento del mismo estilo.

Tanto los defensores de la una, como los partidarios de la otra opinión, parten de: I) un examen interno de las obras; 2) del contexto y 3) de los hechos posteriores, tal como nos permiten conocerlos la escasez de documentos de algunas épocas.

Esto es precisamente lo que me ha inclinado a hacer un primer estudio en el que trataré de precisar las posiciones de los escritores y

\footnotetext{
"moechi", mientras se rechazaba a los apóstatas y homicidas, me permite seguir defendiendo que en las iglesias particulares había a veces prácticas distintas y hasta contrarias en 10 relacionado con esos pecados considerados como fundamentales en la Iglesia primitiva. Y si posCHMANN puede aducir testimonios para probar que en alguna de esas iglesias particulares se seguia la corriente benigna, también podemos aducir otros testimonios que prueban que on algunas otras iglesias se seguia la corriente rígida (POSCHMANN, Pénitence et onction des malades, París 1966, 46-47).

El simple hecho de que renombrados estudiosos de la historia de la penitencia hayan defendido tan decididamente opiniones contrarias, nos indica que los mismos documentos históricos han de ofrecer fundamento a estas opiniones encontradas.

Consciente de esta realidad B. POSCHMANN, Die abendiändische Kirchenbusse in Ausgartg des christliche Altertums, München 1928 estudia la teoria y la práctica en cada una de las grandes iglesias occidentales: Roma, Francia, España, Africa. Tampoco podemos olvidar la forma irlandesa coexistiendo con las formas del continente (G.H. JOYCE, "Private penance in early Church": Joumal of Treological Studies 42 (1941) 18-42).
} 
hasta que pueda sacar conclusiones a partir de la lectura de las opiniones de los estudiosos:

Y la primera conclusión de esta lectura es que ambas corrientes pueden contar en su favor con:

I. argumentos bíblicos, combinados

2. con un ambiente, puesto que una manera de pensar siempre crea un ambiente en torno a sí que la permite imponerse a la contraria si es más fuerte.

3. $y$ unos hechos que prueban su existencia.

I. Argumentos bíblicos: En cuanto a los argumentos bíblicos es necesario reconocer que los defensores del predominio de la corriente benigna han sido más diligentes en buscar una fundamentación bíblica y que han examinado más cuidadosamente los escritos neotestamentarios. El estudio de Hocedez ${ }^{39}$ merece toda la atención y está perfectamente pensado.

En cuanto al apoyo bíblico que puedan encontrar los defensores de la existencia de la corriente rígida, existe una gran pobreza. Está mucho menos estudiada, al menos en lo que yo conozco. Casi toda su argumentación bíblica queda reducida a Heb. 4, 4-8; ro, 26-3 I; I2, I6. En el campo bíblico, pues, se encontrarían en inferioridad de condiciones los defensores de la existencia de una corriente rígida ${ }^{40}$.

2. Ambiente: No olvidemos, sin embargo, que éste es un examen posterior y circunscrito al campo de los principios. Existían razones para defender la existencia de una corriente benigna y hasta de forma predominante. ¿Pero esto puede probarnos que en la práctica sucedía así? Y precisamente entre los católicos los únicos límites que se discuten son los del terreno práctico. Además encontramos también

39. E. HOCEDEZ, "L'Eglise des Saints et le rigorisme primitif": Nouvelle Revue Théologlque 51 (1924) 257-267.

40. Sobre la interpretación de la carta a los Hebreos cfr. como punto de partida, porque da más bibliografía B. POSCHMANN, Pénitence ot onction des malades, París 1966, 20-22; P. BATIFFOL, Etudes d'histoire positive. lére serie. La discipline de l'arcane. Les origines de la pénitence, París 1920, 92, 94; E. VACCANDARD, a.c.: Revue du Clergé Français 20 (1899) 339. 
algunas posiciones intelectuales, no sabemos hasta qué punto apoyadas en el pensamiento bíblico, que hacen aceptable la opinión de quienes defienden la existencia de una corriente inclinada a la rigidez. Podemos resumir dichas razones en las siguientes:

a) La concepción de la Iglesia como comunidad de santos. En el artículo de Hocedez se ve cómo interpretan este concepto - «Iglesia $=$ comunidad de santos $)$ - los defensores de la existencia de la corriente benigna. Pero no pueden asegurar que ésa fuera la interpretación aceptada por la mayoría de los cristianos y por todos los responsables de las distintas iglesias locales ${ }^{41}$.

b. Un fuerte sentimiento y convicción escatológicos, de forma que Hermas, según algunos, parece subordinarlo todo a la escatología ${ }^{42}$.

c. El paralelismo establecido entre la penitencia y el bautismo. Siendo irrepetible el bautismo por ser constituyente de un estado de santidad, también debe serlo la penitencia ${ }^{43}$.

d. Igualmente podría robustecer esta concepción de los inclinados a la rigidez la fuerza de la gracia triunfante en los mártires que permanecieron firmes en la confesión de su fe hasta la muerte. Sin querer olvidar la significación de los numerosos (lapsi) que se dieron en las distintas persecuciones. Hemos de admitir por igual ambos hechos ${ }^{44}$.

e. Finalmente la corriente rigorista se apoyaba en la situación de gheto en que, parte voluntariamente y parte por imposición, vivían los primeros cristianos ${ }^{45}$.

\footnotetext{
41. "L'ancienne organisation du sacrement était née de l'heroïsme de la chrétienté primitive, en un temps où la perte de la grâce du baptême était encore regardée comme une exception et où l'on estimait normal qu'aune exigence ne parût trop sévère au pécheur pour recouvrer son stat de chrétien. Déjà Tertullien se plaignait de se que "très nombreaux" étaient ceux qui reculaient de se mettre à nu par la pénitence publique" (De Penitentia 10,1) (B. POSCHMANN, Pénitence et onction des malades, Paris 1966, 76).

42. B. POSCHMANN, O.c., 34-35.

43. P. BATIFFOL, o.c. 46, 64-65, 71ss.; A BOUDINHON, "Sur l'histoire de la pénitence. A propos d'un ouvrage récent": Revue d'Histoire et de Littérature Religieuses 2 (1897) 323; C. VOGEL, "Un problème pastoral au VI siècle. La poenitentia in extremis au temps de Césaire d'Arles (503-542)": Parole de Dieu et Sacerdoce, Paris-Tournai 1962, 126 not. 1.

44. Th. CAMELOT, "La charité dans la vie des premières communautés chrétiennes": Vie Spirituelle 74(1946)688-701.

45. FLIZ-MARTIN, Hist. de l'Eglis. 398, 429-435.
} 
3. Los hechos que prueban la existencia de ambas corrientes.

Vistos los argumentos que pueden aducirse en favor de la existencia de una u otra corriente, examinemos un poco los hechos. Son ambivalentes y prueban de una forma bastante probable la existencia tanto de la una como de la otra corriente. Nadie se extrañará si yo procuro examinarlos bajo el punto de vista que me permita descubrir y constatar cómo la corriente benigna iba ganando terreno.

a. Primer hecho fundamental: El escrito del Pastor de Hermas.

No considero necesario hacer una descripción de este escrito, como de todos los demás a los que me referiré. Ni es mi intención pararme en la crítica texual de ninguno de ellos. Los estudios existentes ya justifican suficientemente esta toma de posición. Me limitaré a elegir una u otra opinión de los estudiosos, según que la considere más o menos razonable. En nota procuraré indicar los estudios que pueden consultarse.

Generalmente se admite que Hermas es el primero en constituir a la invitación a la penitencia, más bien que a la misma institución penitencial, en objeto de un estudio esvecial ${ }^{46^{\circ}}$. Sin embargo ofrece grandes dificultades de interpretación. Ello justifica la existencia de las más dispares, y hasta contrarias, interpretaciones, al igual que la gran prudencia con que se ha de proceder a la hora de decidirse por alguna de ellas ${ }^{47}$. Unos le ven como el defensor acérrimo de la teoría de los puros —opinión más bien abandonada después de las correcciones de Funck ${ }^{48}$ - pero que por una revelación personal defiende aunque sólo sea de una forma excepcional y como jubileo, la posibilidad de la penitencia postbautismal. Otros le consideran un sencillo predicador de la penitencia dentro del marco común del pensamiento de su época. Algunos le califican de defensor decidido de la corriente benigna. $Y$ finalmente también encontramos a quienes le encuadran en un terreno intermedio ${ }^{49}$. Todos los intér-

46. M.B. CARRA, "Le sacrement de pénitence: aperçu historique": Lumière et Vie 18(1964) 18; B. POSCHMANN, Pénitence et onction des malades, Paris 1966, 32 donde parece inclinarse a defender que el objeto del estudio de Hermas es la misma institución penitencial.

47. M.B. CARRA, a.c., 19.

48. Véase la nota 1.

49 Le consideran como el primero que rompe con la teoria de los "puros": F.X. FUNCK, P. BATIFFOL, A. Von HARNACK, Fr. LOOFS, R. SEEBERG, H. WINDISCH, E. SCHUARZ, H. KOCH, M. Dibelius, H. Weinel, A. PUECH, K. BILMAYer, M.B. CARRA. , 
pretes se han entregado al examen profundo, bajo diversos aspectos, de su doctrina y nadie se extraña de las interpretaciones de los demás, aunque defienda decididamente la suya propia. Comprenden la diversidad de interpretaciones y la atribuyen a las siguientes causas:

I. Singularidad de la obra: es la obra de un hombre sincero, pero simple y de estrecha visión, que se siente llamado a una enseñanza profética aprendida en revelaciones personales.

2. La presentación de su doctrina mediante un estilo rico en imágenes y alegorías, pero descuidado en cuanto a precisión científica. Ello hace necesario admitir ciertas inexactitudes y hasta algunas contradicciones ${ }^{50}$.

"Todo esto, concluye Poschmann, conduce inevitablemente. a conclusiones erróneas, si no se tiene en cuenta la ausencia de rigor científico del autor, y si se toman sus palabras como las de un teólogo) ${ }^{51}$.

Además no podemos olvidar la oscuridad general que envuelve todos estos primeros escritos " $\mathrm{L}$ La Iglesia duda en todas estas discusiones sobre la misma posibilidad de perdonar los pecados cometidos después del bautismo? ¿O se niega a utilizar su poder de perdonar los pecados por considerarlo inoportuno? Hay que confesar que estos documentos no se preocupan lo más mínimo de esta distinción. Sin embargo el problema existe realmente y por ello son posibles tanto las consecuencias de una corriente benigna como las de una corriente rígida ${ }^{52}$. Personalmente no me atrevo a defender la interpretación que encuadra a Hermas entre los rigoristas. Funck ${ }^{53}$ se re-

Le encuadran moviéndose en el marco general de su tiempo: J. STUFLER, A. D'ALES, O. BARDENHEWER, F. HÜNERMANN, P. GALTIER, J. TIXERONT, B. ALTANER, B. POSCHMANN.

Consideran que defiende una posición intermedia: G. RAUSCHEN, K. ADAM, J. HOH, E. AMANN, A. ERHARD. Amplia información en B. POSCHMANN, Pénitence et onction des malades, Paris 1966, 32-33.

50. C. VOGEL, Le pécheur et la pénitence dans l'Eglise ancienne, Paris 1966. FLIZ-MARTIN, Hist. de l'Eglise, 348-349. Pueden verse los textos controvertidos en G. RAUSCHEN, L'eucharistie et la pénitence durant les six premiers siècles, París 1910, 140ss.

51. B. POSCHMANN, o.c. 33.

52. On peut d'ailleurs observer que le sens de cettes hésitations n'est lui-même pas clair. Est-ce que l'Eglise doute de la possibilité même, pour elle, de remettre les péchés commis après le baptême; ou se refuse-t-elle à user de ce pouvoir, estimant inopportune une telle conduite? II faut bien avouer que nos rares documents ne se soucient guère de cette distinction. Probablement ne la supçonnent-ils même pas. Or, en fait, la question se pose bel et bien; et de ce fait les dénégations rigoristes que l'on peut rencontrer, aussi bien que les interventions contraires; demeurent passablement ambiguës" (M.B. CARRA, a.c.: Lumière et Vie 13(1964)23).

53. Véase la nota 1 . 
tractó, y las otras interpretaciones nos hacen ver que sería difícil mantener hoy día esta clasificación de Hermas entre los rigoristas.

Tampoco me parece aceptable la opinión de que Hermas no pasa de ser un sencillo predicador de la penitencia dentro del marco común del pensamiento de su tiempo. Tal vez admitiera esta opinión con ciertas matizaciones, es decir, que Hermas se mueve den. tro de los límites del pensamiento de la corriente benigna de su época, pero sin negar la existencia de una corriente rígida. D'Ales, en su magnífico estudio sobre el Edicto de Calixto, viene a negar la existencia de la corriente benigna en aquel tiempo, o, al menos, que en Hermas no se encuentra indicio alguno de la misma y que no la tiene en cuenta ni influye para nada en él. D'Ales armoniza los pasajes divergentes, y como opuestos -en los que otros autores se apo. yan para defender la existencia de las corrientes benigna y rígidaacudiendo a razones pastorales, que aconsejan hablar de distinta forma según las circunstancias de las personas concretas a las que se dirige en cada uno de ellos. Son contradicciones aparentes que sólo se convierten en reales si no tenemos en cuenta la distinta mentalidad de los diversos grupos de oyentes a que se dirige. Por tanto no se le puede enrolar ni dentro de la corriente benigna, ni tampoco de la rígida, concluye $\mathrm{D}^{\prime}$ Ales $\stackrel{54}{ }$.

No obstante creo que Hermas se encuentra ante las dos corrientes y que elige entre ellas, inclinándose por la benigna, aunque la rígida también deja sus huellas en el escrito.

\footnotetext{
54. D'ALES, L'édit de Calliste, Paris 1914, 70-72. La misma opinión defiende B. POSCHMANN, Pénitence et omction des malades, París 1966, 34-35 afirmando que D'ALES da argumentos convincentes.

No obstante no acepto la opinión de estos autores. Tal opinión me parece estar en oposición con la afirmación "clara de que cáda iglesia particular mantenía cierta independencia en cuanto a la aplicación en la práctica del poder ilimitado de derecho que poseía de perdonar los pecados.Y esto también lo defiende Poschmann. Igualmente me parece difícil defender la opinión de estos dos grandes estudiosos por un segundo dato, también admitido por Poschmann mismo: la existencia de movimientos rigoristas que en tanto arraigan en cuanto que encuentran un suelo predispuesto entre los católicos, y a cuyos centros rigoristas pertenecen no sólo laicos, sino también personas eclesiásticas. Más aún, ambas corrientes coexsitlan en el seno de una misma iglesia particular, según he afirmado "Une étude approfondie montrerait sans doute qu'il y eut un double mouvement, L'Eglise se montrant plus sévère pour les chrétiens ordinaires à fur et mesure qu'elle se montrait plus tendre pour les grands péchęurs (H. RONDET, 'Esquisse d' une histoire du sacrement de pénitence": Nouvelle Revue Théologique $80(1958) 568$. El mismo POSCHMANN o.c. 45-47 comenta el texto de S. Cipriano en el que afirma que, en medio de la benignidad de la iglesia de Africa, existían obispos rigoristas. Y la misma opinión defiende C. VOGEL, Le pécheur et la pénitence dans l'Eglise ancienne, París 1966.
} 
Efectivamente, los documentos prueban la existencia en aquel entonces de un grupo inclinado hacia el rigorismo. Un rigorismo centrado fundamentalmente sobre la castidad ${ }^{55}$ de tal forma que, en la práctica, había convertido la virginidad en condición indispensable para la entrada en el Reino: "La vida cristiana para estos moralistas no era verdadera, si no iba acompañada de una pureza de ángeles. Fuera de la pureza no había salvación" " ${ }^{56}$. Y este grupo estaba ganando adeptos y consistencia en los momentos en que escribe Hermas. La teología posterior lo llamó encratismo. Pero entonces no se pensaba como ahora. San Ireneo habla de esta opinión con cierta simpatía. Presenta a Saturnino y a sus discípulos como (un grupo de personas seductor por su continencia afectadan; que profesan que el matrimonio y la paternidad son obras satánicas. Y a Marción y a los suyos no los sitúa fuera de la Iglesia, sino, dentro de ella como los (continentes) que predican contra el matrimonio y que, en oblicuo, acusan a quien distinguió en la humanidad al hombre y a la mujers ${ }^{57}$. El autor de los Philosophoumena asegura que los encratitas no son disidentes de la fe de la gran Iglesia: "Se dan el nombre de encratitas; pero sobre Dios y sobre Cristo profesan exactamente la misma fe de la

55. 17. Evangile des Egiptiens, se pregunta ¿hasta cuando dominará la muerte? "Elle dominera, tant que vous, femmes, vous enfanterez". Y el Señor insiste: "Je suis venu, disait-il, supprimer les eouvres de la femme" (E. NESTLE, Novi Testamenti graeci supplementum, Leipzig 1896, 72).

Actus Petri cum Simone, cuya primera máxima es la observancia de la caștidad: "Complures aliae honestae feminae, audientes verbum de castitate, recedebant a viris suis, et viri a mulieribus; propter quod vellent caste et munde Deo servire" (R.A. LIPSIUS, Acta Petri, Leipzig, 1891, 85-87).

Acta Thomae aconseja así a los recién casados en su primera noche: "Si vous vous abstenez de ce commerce de souillure, vous deviendrez des temples saints, purs... Vous Aurez préféré les noces pures et véritables. Vous serez le pranymphes (de l'Epoux céleste), ceux qui entrent dans la chambre nuptiale de l'inmortalité et de la lumière". Se comportaron así los dos jóvenes esposos y al día siguiente exponen su alegría a sus padres, como sigue: "Bien loin de moi est l'oeuvre de honte et de confusion, s'écrie l'eppusée: je suis unie à un homme véritable". $Y$ el esposo dice: "Merci à toi, Seigneur, qui m'as eloigné de la souillure, qui as semé en moi la vie, quie $m$ 'as guéri de l'incurable qui $m$ 'as donné la santé de la sagesse" (Acta Thomae, edit. M. BONNET, 11-13, 44).

En este mismo libro se narra cómo Sto. Tomás convence a una mujer para que viva en perfecta castidad. Su esposo desata su lucha contra Sto. Tomás y éste se defiende delante del rey diciendo: "S'il faut, dit-il, obéir à un roi de ce monde, combien plus faut-il obéir au roi céleste, avec purité, hors de tous les plaisir charnels, loin de toute ignominie, de toute luxure, de tout larcin, de toute ignominie, de toute servitude du ventre et toutes les actions mauvaises" (Véase P. BATIFFOLL, O.C: $55-73$ ).

P. BATIFFOL, 0.c. 55-73.

57. S. IRENEO, Contra haereses $1,24,2 ; 28,1$. 
Iglesia) ${ }^{58}$. Y Batiffol opina que el obispo de Cnossos -al que Denys de Corinto pide que «no imponga a los fieles el duro peso de la castidad, sino que tenga en cuenta la debilidad de los más- es un encratita. Ello permite a Batiffol concluir: "El encratismo no es, pues, una secta, sino un espíritu extendido en la Iglesia misma en el siglo II $)^{59}$. Un espíritu que se trasluce también a través de algunos escritos cristianos como en la Secunda Clementis ${ }^{60}$.

Históricamente parece explicarse de alguna manera esta reacción, en sí extremista, como oposición a otra solución, igualmente radical, que invitaba a los cristianos a tener en cuenta y a considerar como indiferentes sus faltas ${ }^{61}$. Así pensaban aquellos a los que Hermas señala como "hipócritas», y cuyas doctrinas califica de "doctrinas extrañas» a la conciencia de la lglesia, "que pervierten a los servidores de Dios, sobre todo a los que han pecado, no permitiéndoles, impidiéndoles su conversión, al darles confianza mediante afirmaciones insensatas) ${ }^{62}$. Parece que pudiera identificarse a éstos con aquéllos a los que, en otro pasaje, presenta como casuistas sin conciencia que, por lucro, enseñan a los hombres (doctrinas según sus concupiscencias), como (hipócritas doctores del mal)" ${ }^{63}$. San Ireneo también se levanta contra los valentinianos que permiten a sus discípulos toda clase de voluptuosidades, según su máxima de que la carne tie-

\footnotetext{
58. Philosophoumena VIII, 20.

59. P. BATIFFOL, Etudes d'histoire positive. Ière serie: La discipline de l'arcane. Les origines de la pénitence, París 1920, 52-53.

$Y$ ya he indicado cómo Denys de Corinto (hacia el año 165-170) admite que, si bien la norma era admitirlos a la penitencia, sin embargo había quienes no los admitian; por lo cual él escribe sus dos cartas contra las demasiadas exigencias en materia sexual y contra la negación del perdón a estos pecadores (Véase EUSEBIO, Historia Eclesiástica IV, 23, 6 cit. por B. POSCHMANN, Pénitence et onction des malades, París 1966, 42). Reconozco que existe discusión sobre el sentido de su expresión puesto que A. von HARNACK y H. KOCH defienden que dicha expresión no significa más que la admisión a la penitencia, pero no a la reconciliación; mientras que DE LABRIOLLE, D'ALES, A. EHRHARD, J. KOCH y POSCHMANN sostienen que se trata realmente del perdón (B. POSCHMANN, o.c. 42, not. 2). Igualmente conozco la carta de S. CIPRIANO, Ep. 55, 21 en que se nos dice que algunos de sus antepasados (algunos) negaban la reconciliación.

60. II Clementis $7,8,9,13,15$.

61. De hecho H. RONDET pone ambos movimientos en relación entre sí: "Ces reactións des milieux héretiques nous prouvent que l'Eglise, sur plus d'un point, était plus sûre de sa pratique liturgique et sacramentaire que des théories par lesquelles on pouvait chercher à la justifier. Mais elle dut cependant s'expliciter progressivement. Les événements l'ayant amenée à montrer, 4 l'exemple de son maitre, une miséricorde grandissante à l'égard des pécheurs, elle vit se dresser contre elle, au nom de la Tradition, des héretiques nouveaux ("Esquisse d'une histoire du sacrement de pénitence": Nouvelle Revue Théologique 80(1958)566).
}

62. SIm. VIII, 6, 5 .

63. Sim. IX, 19. 
ne derecho a la carne, como el espíritu al espíritu ${ }^{64}$. Igualmente los carpocratistas enseñan que el hombre se salvará por la fe y la caridad, mientras que todo lo demás es indiferente: el bien y el mal, lo justo y lo injusto no existen más que en la opinión de los hombres. En sí mismos no existen ${ }^{65}$. Como contrarreacción habría surgido la corriente rígida.

Pero no sólo existía en tiempo de Hermas dicha tendencia a la rigidez, sino que además Hermas la conocía ${ }^{66}$. Son textos oscuros, es cierto. Pero por eso mismo es necesario interpretarlos a través de otros pasajes más claros fruto de la misma mentalidad. Creo que el texto que utiliza D'Ales para probar que en Hermas no existe reminiscencia alguna de las dos tendencias, más bien demuestra que existían las dos y que Hermas las conocía y las tenía en cuenta. Lo que no encuentro en el citado texto es una aprobación explíita de la corriente rígida. Sencillamente es una constatación de que existen tales doctores que piensan de esa manera rígida, pero sin concederles autoridad ni aceptar su opinión ${ }^{67}$. A lo largo de la historia de la penitencia, toda afirmación que tienda a robustecer la tendencia benigna nos está descubriendo, indirectamente, la existencia y la oposición de la tendencia rígida, que estaba combatiendo por conquistar sus puestos. Creo, pues, con Batiffol y otros, que el escrito del Pastor de Hermas es la primera reacción escrita conocida de la sentencia benigna ${ }^{68}$. Su tesis fundamental es dar esperanza al cristiano que después del bautismo ha caído en el pecado, con tal de que se dé un auténtico arrepentimiento. Y la misión que se atribuye a sí mismo el Pastor es "el anuncio a los santos caídos, que, aún para ellos, existe todavía la posibilidad de recuperar la salud perdida, a condición de que sin

\footnotetext{
64. Contra haereses $1,6,3$.

65. Contra haereses $1,25, \mathrm{cfr} I, 26,3 ; 28,2 ; 31,2$.

66. Mand. IV, 3; RAUSCHEN, o.c. 139ss.

67. La misma opinión defiende B. POSCHMANN, Pénitence et onction des malades, Paris 1966, 34. Sabemos que Hermas no tiene formación alguna teológica, que no le interesan de ninguna manera las cuestiones especulativas, que es un cristiano sincero, fervoroso y vivamente preocupado de los problemas entre los que se mueve su vida cristiana. Por tanto no describe los problemas teológicos, sino la vida sencilla y las dificultades con que tropieza la vida cristiana. Describe las corrientes doctrinales no en cuanto tales, sino en cuanto que tiene repercusiones en la vida práctica de los cristianos (FLITZ-MARTIN, Histoire de l'Eglise, 348-349).

68. P. BATIFFOL, o. c. 54; H. RONDET, “Esquisse d'une histoire du sacrement de pénitence": Nouvelle Revue Théologique 80 (1958) 566: "Hermas représente la réaction d'un moraliste de bon sens qui, sans laisser de precher l'idéal, connait la faiblesse humaine" (con citas que da en nota Rondet).
} 
dilación se arrepientan de todo corazón” ${ }^{69}$. Resumiría el pensamiento de Hermas con Batiffol:

(Hermas mantiene el ideal de la pureza bautismal, esta castidad de verdad, de la que no deben apartarse lo más mínimo los cristianos. Concibe la Iglesia como una Iglesia de perfectos. Pero siente la necesidad de la indulgencia, y la lucha entre el ideal y la indulgencia es el punto central del objeto del escrito de Hermas. No circunscribe la salvación a los límites de la Iglesia visible: habrá almas que se conviertan y que no serán incorporadas a la torre mística, pero sí a un lugar más humilde. La torre mística está guardada por siete mujeres que son las siete virtudes: la primera es la fe que tiene como hija a la castidad. Las otras virtudes son la simplicidad, la ciencia, la inocencia, la pudicia y la caridad. Cuantos realicen las obras de estas virtudes tendrán una mansión en la torre con los santos de Dios. Pero entre todas estas virtudes la más bella, la preferida, es la continencia y "quien observare la continencia será dichoso en esta vida y heredará la eterna $)^{70}$. Aquellos a quienes el Señor elige para la vida eterna, permanecerán sin tacha, serán "puros» y su corazón inmaculado. La vida cristiana consiste en creer y temer a Dios, y ser continente $^{\text {t1 }}$.

Es un encratismo mitigado: ser continente para Hermas consiste en abstenerse de toda malicia y practicar el bien. El encratismo de Hermas prohibe el adulterio, la fornicación, el robo, el dolo, el falso testimonio, la blasfemia, la hipocresía; practicará en cambio, la $\mathrm{fe}$, el temor de Dios, la caridad, la concordia, la paciencia; socorrerá a las viudas, huérfanos y pobres; será hospitalario y limosnero ${ }^{72}$. Estos mandamientos son elementales y no representan más que los deberes comunes de la vida cristiana.

La vida cristiana pierde así algo de su heroísmo para convertirse en algo realizable. Así y todo le parece a Hermas difícil de practicar. El Pastor asegura que el cristiano no tiene más que despertar en sí la concupiscencia del bien y detestar la concupiscencia del mal, para poder dirigirse a donde desee, como se dirige a un caballo dominado.

\footnotetext{
69. J. REVILLE, La valeur du tómoignage historique du Pasteur d'Hermas, Paris 1900, 11, cit. por P. BATIFFOL. O. c. 57.

70. Vis. III, 8.

71. Vis. IV, 2 et 3 ; Mand. I et VI, 1

72. Mand. VIII.
} 
Pero esta pedagogía le parece a Hermas sobrehumana. Duda que tales preceptos, en sí hermosos, puedan ser observados porque son (cexcesivamente duros). El Pastor replica que la energía del hombre puede ser suficiente: "si dices que pueden ser observados, los observarás cuidadosamente). Y la obligación de observarlos es imperiosa: si no los observas no habrá salvación ni para ti, ni para tus hijos, ni para tu casa». Sin embargo afirma inmediatamente que el cristiano caído no debe desesperar de su salvación: que se convierta de todo corazón, que viva en justicia el resto de su vida y que Dios está dispuesto a curarle de sus faltas anteriores.

Así la doctrina de Hermas es una reacción contra el rigorismo, conservando sus preceptos pero acomodándolos $\mathrm{e}$ interpretándolos con benignidad; e igualmente es una afirmación de la fuerza salvadora del arrepentimiento. Hermas, en efecto, no puede eceptar que Dios sea un dueño duro y celoso. Dios es magnánimo y desde el momento en que ha llamado a un alma a la fe, es que quiere salvarla ${ }^{73}$. Y añade: "Dios no guarda resentimiento contra quienes reconocen sus faltas, y les es misericordioso $"{ }^{74}$. Pero esta paternidad misericordiosa y magnánima, este deseo de salvación de los bautizados, es ineficaz sin el movimiento del pecador, que no puede ser curado por Dios si él mismo no quiere su curación)" ${ }^{75}$.

Se trata, pues de una reacción un poco tímida de la tendencia hacia la benignidad. Tal vez fuera que la corriente benigna se encontraba en inferioridad en el momento en que escribe el Pastor de Hermas, porque las limitaciones que encontramos en el Pastor de Hermàs pueden ser consideradas como imposiciones o concesiones hechas a la corriente rígida. De hecho siente la necesidad de atribuir cuanto expone a la Iglesia, como si temiera manifestar su pensamiento propio; adopta un estilo alegórico, que da pie a tantas interpretaciones por su oscuridad; lo limita a una sola vez; lo considera gracia especial y la presenta como jubileo. No es una afirmación categórica y tajante, sino con ciertas limitaciones. Se esfuerza por ser cauto en su exposición y en la afirmación de la posibilidad de la penitencia postbautismal. Aún los mayores defensores de que Hermas pertenece a

\footnotetext{
73. Sim. VIII, 11

74. Sim. IX, 23.

75. P. BATIFFOL, Etudes d'histoire positive, lère serie: La discipline de I' arcane. Les origines de la pénitence, Paris 1920, 58-61.
} 
la escuela de la benignidad, admiten, sin enfado, que Hermas mantiene un cierto encratismo, un encratismo moderado.

También pudieran interpretarse estas limitaciones como consecuencia de que en sus días todavía no se hubiera establecido de una manera firme institución alguna penitencial. Al menos de Hermas no puede deducirse. Los primeros testimonios claros y explícitos de dicha institucionalización creen que se deben a Tertuliano y $\mathrm{S} . \mathrm{Ci}$ priano. Y esto favorecía aún más la idea defendida en estas páginas.

Concluyo, pues, con Batiffol:

"La doctrina esencial de Hermas es una reacción contra el rigorismo, conservando sus preceptos, pero interpretándolos con benignidad, y afirmando la fuerza de la virtud del arrepentimiento. En efecto, Hermas no concibe a Dios como un dueño duro y severo. El Señor es magnánimo, y cuando ha llamado a las almas a la fe, es que quiere salvarlas. Pero esta paternidad misericordiosa y magnánima, este deseo divino de salvación de las almas bautizadas, es ineficaz sin el movimiento propio del pecador, que no podría ser curado por el Dios que quiere su curación ${ }^{76}$.

Hermas es bien aceptado dentro de la Iglesia romana ${ }^{77}$ y su pensamiento se deja sentir en otras iglesias particulares. S. Ireneo y Tertuliano lo citan como Escritura; Clemente de Alejandría como Escritura divina; Orígenes nos da una indicación preciosa en cuanto a la idea que estamos defendiendo de la existencia de las dos corrientes. Afirma que es una "Escritura recibida en la iglesia romana, pero no reconocida como divina por todos"); y la iglesia romana, en el canon llamado de Muratori, precisa que no es una composición apostólica, sino reciente. La iglesia de Roma, para mantener el equilibrio del prestigio creciente del escrito de Hermas, admite dicho prestigio pero indica que no tiene el carácter de escrito apostólico o profético de los libros incluidos en el citado canon, que es leído públicamente, como la Prima Clementis, pero que no obstante expresaba el pensamiento y la doctrina del presbiterado romano. Es comunmente admitido que el mismo Tertuliano se ha inspirado en Hermas para la redacción del De Poenitentia ${ }^{78}$.

\section{ZaCARIAS Herrero}

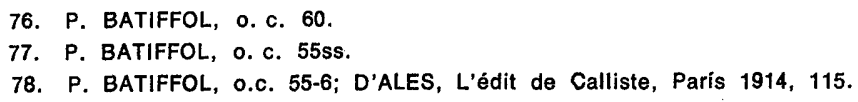

